\title{
PERSISTENT INFECTION OF NEURAL CELL LINES BY HUMAN CORONAVIRUSES
}

\author{
Nathalie Arbour and Pierre J. Talbot \\ Laboratory of Neuroimmunovirology \\ Institut Armand-Frappier \\ Université du Québec \\ Laval, Québec, Canada H7V 1B7
}

\section{ABSTRACT}

Human coronaviruses (HCV) have been associated mainly with infections of the respiratory tract. Accumulating evidence from in vitro and in vivo observations is consistent with the neurotropism of these viruses in humans. To verify the possibility of a persistent infection within the central nervous system (CNS), various human cell lines of neural origin were tested for their ability to maintain chronic infection by both known strains of $\mathrm{HCV}, \mathrm{OC} 43$ and 229 E. Production of infectious progeny virions was monitored by an immunoperoxydase assay on a susceptible cell line and viral RNA was observed after RT-PCR. Astrocytic cell lines U-373 MG and U-87 MG did not sustain a persistent HCV-229E infection, even though they were susceptible to an acute infection by this virus. On the other hand, these two cell lines could maintain a persistent infection by HCV-OC43 for as many as 25 cell passages (about 130 days of culture). Relatively stable titers of infectious viral particles, as well as apparently constant amounts of viral RNA were detected throughout the persistent infection of U-87 MG cells. However, persistent infection of U-373 MG cells was accompanied by the detection of infectious viral particles from passage 0 to passage 13 and then from passage 20 to the end of the experiment. This gap in the production of infectious virions was correlated by a drop in the apparent amount of viral RNA detected at passages 15 and 20 . These results confirm the ability of HCV-OC43 to persistently infect cells of an astrocytic lineage and, together with our previous observations of $\mathrm{HCV}$ infection of primary cultures of human astrocytes and the detection of HCV RNA in human brains, are consistent with the possibility that this human coronavirus could persist in the human CNS by targeting astrocytes.

\section{INTRODUCTION}

Human coronaviruses (HCV) cause up to one-third of common colds (Myint 1994). Neonatal nosocomial respiratory coronavirus infections appear to be frequent and may be 
associated with apnea (Sizun et al. 1995). Other pathologies have sporadically been associated with HCV such as pneumonia, perimyocarditis, meningitis, radiculitis (Riski and Hovi, 1980), as well as diarrhea (Resta et al. 1985). Increasing evidence from animal models and studies in humans suggest a neurotropism for these viruses.

The murine counterpart of HCV, murine hepatitis virus (MHV), has been studied as an animal model of a virus-induced disease of the central nervous system (CNS) (ter Meulen et al. 1989). After intranasal inoculation, MHV enters the CNS of mice via the olfactory nerve and then spreads to the brain (Barnett and Perlman 1993). Moreover, a neurotropic MHV was shown to enter the CNS of primates after peripheral inoculation (Cabirac et al. 1994).

Salmi et al. (1982) detected intrathecal antibody synthesis to HCV in humans, particularly in multiple sclerosis patients, suggesting a CNS infection. Moreover, HCV RNAs have repeatedly been detected in human brains (Stewart et al. 1992, Murray et al. 1992, Arbour and Talbot 1997). Finally, we have recently shown that HCV could infect primary cultures of human neural cells (Bonavia et al. 1997). We speculate that HCV could persistently infect human neural cells since MHV RNA could be detected in the brains of infected mice for a long period of time after the initial infection (Adami et al. 1995, Rowe et al. 1997) and that HCV were detected in human brains and are able to infect human neural cells both in primary and immortalized cultures. Since primary cultures do not allow us to perform a long time-scale study that is involved for viral persistence, we have used cell lines representative of different neural cell types to verify the possibility of persistent HCV infections. Viral RNA and infectious viral particles were monitored during a prolonged infection cycle.

\section{MATERIALS AND METHODS}

\subsection{Virus and Cell Lines}

Both HCV strains (229E and OC43) were originally obtained from the American Type Culture Collection (ATCC; Rockville, MD), plaque-purified twice and grown on either L132 cells (229E) or HRT-18 cells (OC43), as described previously (Jouvenne et al. 1992, Mounir and Talbot 1992). The third passage of HCV-229E with a titer of $5.5 \times 10^{5}$ $\mathrm{TCID}_{50} / \mathrm{ml}$ and the fourth passage of HCV-OC43 with a titer of $5.15 \times 10^{5} \mathrm{TCID}_{50} / \mathrm{ml}$, from laboratory stocks kept at $-90^{\circ} \mathrm{C}$, were used for all experiments. Human neuronal and glial cell lines: H4, SK-N-SH, MO3.13, U-373 MG, U-87 MG, were obtained and cultured as already described (Talbot et al. 1994). Cell monolayers at 60-80\% confluence were infected in $25 \mathrm{~cm}^{2}$ culture flasks with $0.5 \mathrm{ml}$ of viral suspension and incubated 2 hours at 33 ${ }^{\circ} \mathrm{C}$, with periodical agitation. Cell monolayers were then washed with PBS and grown in the regular cell culture medium at $37^{\circ} \mathrm{C}$. Cells were passaged by trypsination every 4-8 days. Samples of supernatants and cells were kept for viral titration at each passage and cells kept at each fifth passage for RNA extraction.

\subsection{Immunoperoxidase Assay for Quantitation of Infectious Virus Titers}

The immunoperoxydase assay for quantitation of infectious virus titers was performed as described (Bonavia et al. 1997). Antiviral mouse monoclonal antibody 1.10-C.1 (anti-HCV-OC43) was produced in our laboratory by standard hybridoma technology. 


\subsection{Preparation of RNA and Reverse-Transcription Polymerase Chain Reaction}

To extract total cellular RNA from infected or controls cells, cell monolayers were washed twice with PBS and then kept at $-90{ }^{\circ} \mathrm{C}$ until RNA extraction. Cells were lysed with GIT buffer (4 M guanidine isothiocyanate, $2.5 \mathrm{mM} \mathrm{Na}$ acetate, $12 \mathrm{mM}$ 2-mercaptoethanol). Lysates were passed through a 26G needle at least 6 times and then layered onto a cesium chloride cushion ( $5.7 \mathrm{M}$ cesium chloride, $2.5 \mathrm{mM}$ Na acetate) for a 12 to 20 hours centrifugation at $150000 \mathrm{x} g$. The supernatant was removed and the RNA pellet resuspended in sterile dd $\mathrm{H}_{2} \mathrm{O}$. The pair of primers used for HCV-OC43 amplification as well as the one for control gene (glyceraldehyde-3-phosphate dehydrogenase) are described in Table 1. A mixture of $40 \mathrm{pmol}(4 \mu \mathrm{l})$ of the inverse-complementary primer and about $5 \mu \mathrm{g}$ of total cellular RNA was incubated at $65^{\circ} \mathrm{C}$ for $5 \mathrm{~min}$ to denature RNA, followed by a slow cool down to $37^{\circ} \mathrm{C}$ for annealing. Reverse transcription with Moloney murine leukemia virus reverse transcriptase (50 U; Boehringer Mannheim) was performed at $42{ }^{\circ} \mathrm{C}$ for $90 \mathrm{~min}$ in the presence of $60 \mathrm{U}$ of RNA Guard (Pharmacia), $0.4 \mathrm{mM}$ of each dNTP (Boehringer Mannheim), 1X Reverse Transcriptase buffer [50 mM Tris-HCl pH 8.3, $40 \mathrm{mM} \mathrm{KCl}, 5 \mathrm{mM} \mathrm{MgCl}{ }_{2} 0.5 \%$ Tween $\left.{ }^{\circledR} 20(\mathrm{v} / \mathrm{v})\right]$ and $10 \mathrm{mM}$ dithiothreitol (Boehringer Mannheim). For PCR, one fifth of the synthesized cDNA was incubated in the presence of 20 pmol of the $\mathrm{O} 1$ and $\mathrm{O} 3$ primers, or 50 pmol of the GAPDH-H and GAPDH-I primers, $2.5 \mathrm{mM} \mathrm{MgCl}_{2}$ (1.5 mM in the case of GAPDH) (BIO/CAN), 1X PCR buffer (10 mM Tris- $\mathrm{HCl} \mathrm{pH} \mathrm{8.3,1.5} \mathrm{mM} \mathrm{MgCl}, 50 \mathrm{mM} \mathrm{KCl}$ ) (Boehringer Mannheim) and $0.4 \mathrm{mM}$ of each dNTP (Boehringer Mannheim) at $94^{\circ} \mathrm{C}$ for $5 \mathrm{~min}$ and at $60^{\circ} \mathrm{C}\left(50^{\circ} \mathrm{C}\right.$ for GAPDH) for another 5 min. After addition of the Taq DNA polymerase ( $2.5 \mathrm{U}$; Boehringer Mannheim), 30 cycles of 2 min at $72{ }^{\circ} \mathrm{C}, 1 \mathrm{~min}$ at $94^{\circ} \mathrm{C}$ and $2 \mathrm{~min}$ at $60^{\circ} \mathrm{C}\left(50^{\circ} \mathrm{C}\right.$ for GAPDH) were performed with a final elongation step of $10 \mathrm{~min}$ at $72^{\circ} \mathrm{C}$. The DNA amplicons were separated by electrophoresis in a $1.5 \%(\mathrm{w} / \mathrm{v})$ agarose gel containing $1 \mu \mathrm{g} / \mathrm{ml}$ ethidium bromide.

\section{RESULTS and DISCUSSION}

\subsection{Quantitation of Infectious Progeny Virions}

Although the human astrocytic glial cell lines U-373 MG and U-87 MG were previously shown to be acutely infectable by HCV-229E (Talbot et al. 1994), no infectious viral particles could be detected after the 5 th cell passage during a persistent infection (data not shown). Therefore, it appears that astrocytic cell lines did not sustain a persistent infection by HCV-229E. These results could be easily compared with the ones obtained with

Table 1. Primers for RT-PCR

\begin{tabular}{|c|c|c|}
\hline \multirow{2}{*}{$\frac{\text { RNA amplified }}{\text { HCV-OC43 nucleoprotein }}$} & \multicolumn{2}{|c|}{ Primers-corresponding region } \\
\hline & $5^{\prime}$ - CCCAAGCAAACTGCTACCTCTCAG - $3^{\prime}$ & O1-sense: $215-238$ \\
\hline & 5' -GTAGACTCCGTCAATATCGGTGCC - 3' & O3- antisense: $497-520$ \\
\hline GAPDH $^{2}$ & 5' - GTGAAGGTCGGAGTCAACG - $3^{\prime}$ & GAPDH-H-sense: $10-68$ \\
\hline & 5' - CACCTGGTGCTCAGTGTAGC - 3' & GAPDH-I-antisense: $824-843$ \\
\hline
\end{tabular}

'(Stewart et al. 1992); (Kamahora et al. 1989)

2 (Ercolani et al. 1988) 
primary cultures of human astrocytes where the HCV-229E infection could only be detected by RT-PCR and not by immunofluorescence or by production of infectious progeny virions (Bonavia et al. 1997). Therefore, it is possible that HCV-229E could infect astrocytic cells but that the infection is rapidly cleared. These results suggest that the presence of HCV-229E in human brains may not involve astrocytes. However in situ hybridization assays from HCV-229E RNA positive human brain samples will be necessary before such a conclusion can definitively be reached.
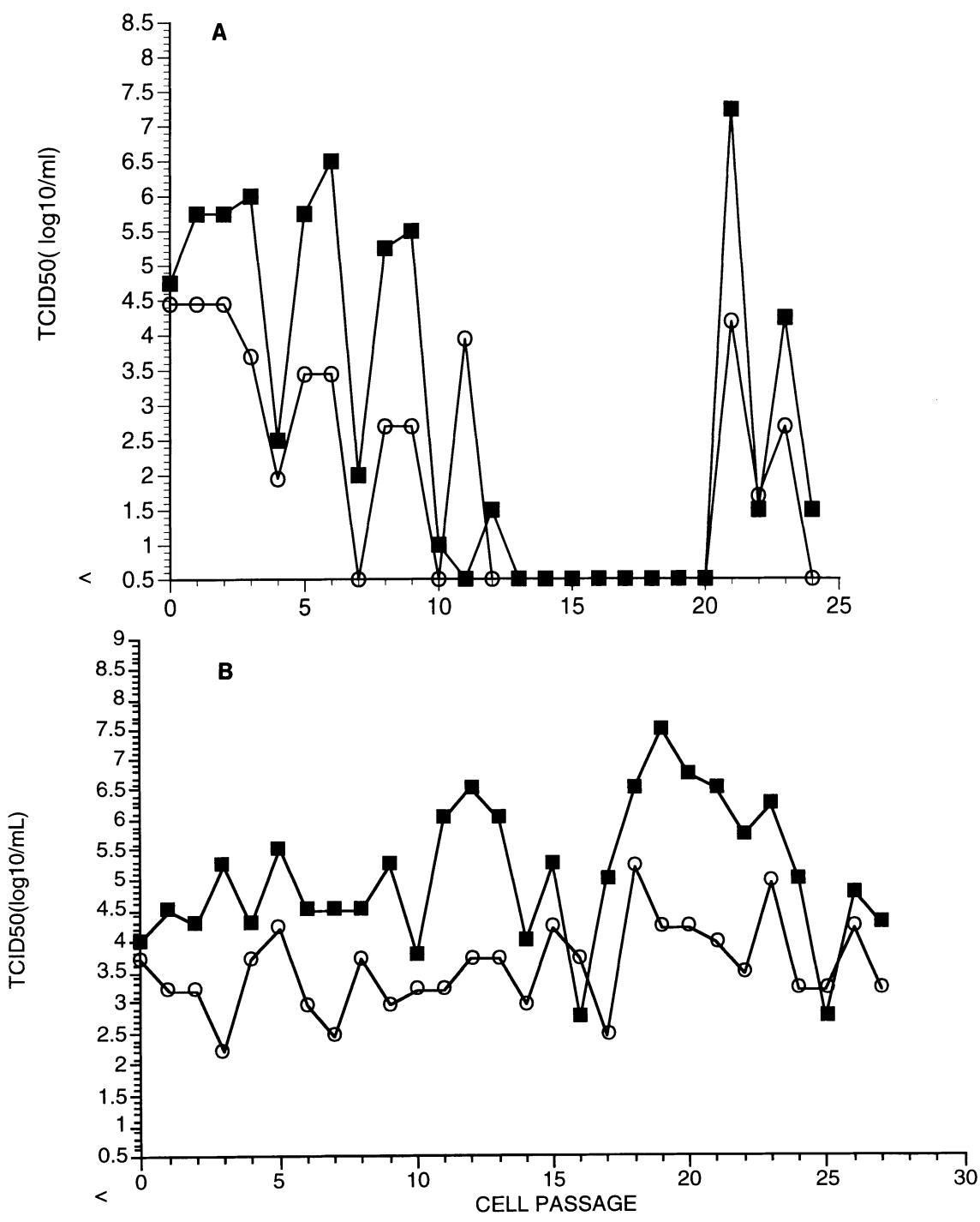

Figure 1. Infectious virus titers from HCV-OC43 persistent infections of astrocytic cell lines. Panel A: U-373 MG; Panel B: U-87 MG. a: extracellular, O: intracellular. 
Persistent infection of the same astrocytic cell lines by HCV-OC43 did result in the production of infectious virions as late as the 25th cell passage (about 130 days in culture). Figure 1 shows the infectious viral titers obtained from persistently infected U-373 MG and U-87 MG cell lines (panels A and B, respectively). In both cases, viral titers obtained for the extracellular component were higher than for the intracellular components. These astrocytic cell lines did produce infectious virions in amounts comparable to that obtained after infection of the reference cell line HRT-18 (data not shown). Approximately $10 \%$ of U-87 MG cells were infected in the culture, as estimated by immunofluorescence (data not shown). This percentage of infected cells appears to be sufficient to maintain the presence of virus in the culture. Collins and Sorensen (1986) previously showed that U-87 MG cells could be persistently infected with HCV-OC43 and release infectious virions, although infection was monitored on a much shorter time scale of 28 days.

No virus was detected between passages 13 and 20 of the persistently infected U373 MG cell culture, despite the presence of viruses at the beginning and at the end of the culture, particularly in the extracellular compartment (Fig. 1, panel A). At the end of the culture, about $5 \%$ of U-373 MG cells were infected, as shown by immunofluorescence (data not shown). Persistent infections by HCV-229E and HCV-OC43 of other neural cell lines representative of human neurons (H4) and oligodendrocytes (MO3.13) were also observed, including production of infectious virions after more than 100 days of culture (data not shown).

\subsection{Detection of HCV-OC43 RNA}

Figure 2 shows RT-PCR results obtained from $\mathrm{HCV}-\mathrm{OC} 43$ persistent infection of U373 MG and U-87 MG cells. The RT-PCR assay was performed on RNA extracted from acutely infected cells (lanes A) and non-infected cells (lanes N). GAPDH RNA could be amplified in each case (data not shown), indicating that RNA was suitable for amplification even for non-infected cells, where no viral RNA could be detected. Viral RNA could be detected at every passage we looked at : P2, P5, P10, P15, P20 and P25 (both cell lines) and P28 (U-87 MG only). Apparently comparable amounts of viral RNA were detected in

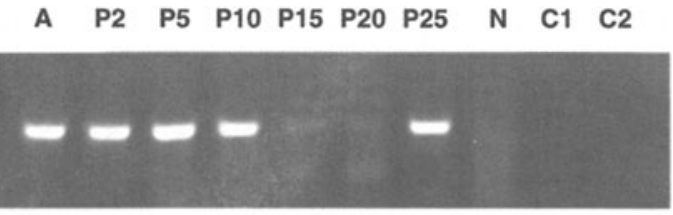

B
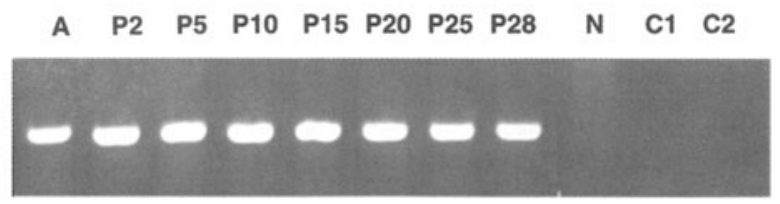

Figure 2. Detection of HCV-OC43 RNAs in persistently infected cells by RT-PCR visualized on a $1.5 \%(\mathrm{w} / \mathrm{v})$ agarose gel containing ethidium bromide. Panel A: U-373 MG, Panel B: U-87 MG. A: acute infection, Px, cell passage number, N: non-infected cells, C1: RT negative control and C2: PCR negative control. 
acute and persistently infected cells. For U-87 MG cells, comparable amounts of viral RNA could be amplified at each passage, which is consistent with a more or less constant amount of viral RNA in the culture. Other authors have been able to detect viral RNA during a persistent HCV-OC43 infection of U-87 MG cells (Collins and Sorensen 1986). During the persistent infection of U-373 MG cells, we observed that apparently less viral RNA was detectable at P15 and P20, even though the same amount of total cellular RNA was used for RT-PCR in each case. When these results are compared to those of the immunoperoxydase experiments (Fig. 1, panel A), we observe that passages where no infectious virus was detected (13-20) correspond to low viral RNA levels.

We have recently shown that HCV-OC43 could infect primary cultures of human fetal astrocytes, adult microglia and adult astrocytes, as monitored by the immunofluorescence detection of viral proteins (Bonavia et al. 1997). It is therefore not surprising that astrocytic cell lines also supported a $\mathrm{HCV}-\mathrm{OC} 43$ infection. Interestingly, in mice, the murine strain MHV-JHM infects astrocytes after an intranasal inoculation (Sun and Perlman 1995). Moreover during the chronic demyelination induced in infected mice, astrocytes are the predominant cells expressing inflammatory cytokines such as IL-1 $\beta$ and IL-6, as well as nitric oxide (Sun et al. 1995) probably involved in tissue damage, such as demyelination. In addition, in situ hybridization combined with immunohistochemistry performed on monkey brains after intracerebral infection has shown that astrocytes are the target cells in white matter during acute infection by MHV-JHM (Murray et al. 1997). Our results, combined with the work of other research teams, are consistent with a potential role of astrocytes in CNS infection by human coronaviruses.

\section{ACKNOWLEDGMENTS}

We thank Francine Lambert for excellent technical assistance. N. Arbour is grateful to the Institut Armand-Frappier for studentship support and P. J. Talbot to the Fonds de la recherche en santé $d u$ Québec for a senior scholarship. This work was supported by an operating grant from the Medical Research Council (MRC) of Canada to P.J.T.

\section{REFERENCES}

Adami, C., Pooley, J., Glomb, J., Stecker, E., Fazal, F., Fleming, J.O., and Baker, S.C., 1995, Evolution of mouse hepatitis virus (MHV) during chronic infection: quasispecies nature of the persisting MHV RNA, Virology, 209:337-346.

Arbour, N., and Talbot, P.J., 1997, unpublished observations.

Barnett, E.M., and Perlman, S., 1993, The olfactory nerve and not the trigeminal nerve is the major site of CNS entry for mouse hepatitis virus, strain JHM, Virology 194:185-191.

Bonavia, A., Arbour, N., Yong, V.W., and Talbot, P.J., 1997, Infection of primary cultures of human neural cells by human coronaviruses 229E and OC43, J. Virol. 71:800-806.

Cabirac, G.F., Soike, K.F., Zhang, J.Y., Hoel, K., Butunoi, C., Cai, G.Y., Johnson, S., and Murray, R.S., 1994, Entry of coronavirus into primate CNS following peripheral infection, Microb. Path. 16:349-357.

Collins, A.R., and Sorensen, O., 1986, Regulation of viral persistence in human glioblastoma and rhabdomyosarcoma cells infected with coronavirus OC43, Microb. Path. 1: 573-582.

Ercolani, L., Florence, B., Denaro, M., and Alexander, M., 1988, Isolation and complete sequence of a functional human glyceraldehyde-3-phosphate dehydrogenase gene, J. Biol. Chem. 263:15335-15341.

Jouvenne, P., Mounir, S., Stewart, J.N., Richardson, C.D., and Talbot, P.J., 1992, Sequence analysis of human coronavirus 229E mRNAs 4 and 5: evidence for polymorphism and homology with myelin basic protein, Virus Res. 22:125-141. 
Kamahora, T., Soe, L.H., and Lai, M.M.C., 1989, Sequence analysis of nucleocapsid gene and leader RNA of human coronavirus OC43, Virus Res. 12:1-9.

Mounir, S., and Talbot, P.J., 1992, Sequence analysis of the membrane protein gene of human coronavirus OC43 and evidence for $O$-glycosylation, J. Gen. Virol. 73:2731-2736.

Murray, R.S., Brown, B., Brian, D., and Cabirac, G.F., 1992, Detection of coronavirus RNA and antigen in multiple sclerosis brain, Ann. Neurol. 31:525-533.

Murray, R.S., Cai, G.Y., Soike, K.F., and Cabirac, G.F., 1997, Further observations on coronavirus infection of primate CNS, J. Neurovirol. 3:71-75.

Myint, S.H., 1994, Human coronaviruses-a brief review, Rev. Med. Virol. 4:35-46.

Resta, S., Luby, J.P., Rosenfeld, C.R., and Siegel, J.D., 1985, Isolation and propagation of a human enteric coronavirus, Science 229:978-981.

Riski, H., and Hovi, T., 1980, Coronavirus infections of man associated with diseases other than the common cold, J. Med. Virol. 6:259-265.

Rowe, C.L., Baker, S.C., Nathan, M.J., and Fleming, J.O., 1997, Evolution of mouse hepatitis virus: detection and characterization of spike deletion variants during persistent infection, J. Virol. 71:2959-2969.

Salmi, A., Ziola, B., Hovi, T., and Reunanen, M., 1982, Antibodies to coronaviruses OC43 and 229E in multiple sclerosis patients, Neurology 32:292-295.

Schreiber, S.S., Kamahora ,T., and Lai, M.M.C., 1989, Sequence analysis of the nucleocapsid protein gene of human coronavirus 229E, Virology 169:142-151.

Sizun, J., Soupre, D., Legrand, M.C., Giroux, J.D., Rubio, S., Cauvin, J.M., Chastel, C., Alix, D., and de Parscau, L., 1995, Neonatal nosocomial respiratory infection with coronavirus: a prospective study in a neonatal intensive care unit, Acta Paediatr. 84:617-620.

Stewart, J.N., Mounir, S., and Talbot, P.J., 1992, Human coronavirus gene expression in the brains of multiple sclerosis patients, Virology 191:502-505.

Sun, N., and Perlman, S., 1995, Spread of a neurotropic coronavirus to spinal cord white matter via neurons and astrocytes, J. Virol. 69:633-641.

Sun, N., Grzybicki, D., Castro, R.F., Murphy, S., and Perlman, S., 1995, Activation of astrocytes in the spinal cord of mice chronically infected with a neurotropic coronavirus, Virology 213:482-493.

Talbot, P.J., Ékandé, S., Cashman, N.R., Mounir, S., and Stewart, J.N., 1994, Neurotropism of human coronavirus 229E, Adv. Exp. Med. Biol. 342:339-346.

ter Meulen, V., Massa, P.T., and Dörries, R., 1989, Coronaviruses, in: Handbook of clinical neurology: viral disease, revised series, Volume 12 (P.J. Vinken, G.W. Bruyn, and H.L. Klawans, eds.), Elsevier, New-York, pp. 439-451. 